\title{
A proteção dos sinais distintivos como promoção da ética e da sustentabilidade em um mercado de livre concorrência
}

\author{
The protection of distinctive signs as means of \\ promoting ethics and sustainability in a free market \\ competition
}

Maitê Cecilia Fabbri Moro*

\section{Resumo}

Para que a livre iniciativa e a livre concorrência, garantidas na Constituição Brasileira, sejam efetivas, é imprescindível que os concorrentes possam se diferenciar. A diferenciação no mercado é que garante a concorrência. Os sinais distintivos são instrumentos de identificação e diferenciação do empresário, seus produtos e serviços no mercado. Igualmente assegurada pela Constituição Brasileira, a proteção aos sinais distintivos garantem uma concorrência ética e leal, assim incentivando a sustentabilidade empresarial e a concorrência. A marca é o principal elemento diferenciador da empresa nos dias de hoje. Apesar de pelo registro no Instituto Nacional da Propriedade Industrial (INPI) se outorgar um direito de exclusividade a um único titular, esse direito não significa uma distorção da livre concorrência, mas sim um elemento necessário para mantê-la e promovê-la.

Palavras-chave: Constituição. Livre concorrência. Livre iniciativa. Propriedade industrial. Sinais distintivos. Marca.

\section{Abstract}

For efectiveness of freedom of initiative and freedom of competition, guaranteed in the Brazilian Constitution, it is important that the competitors can differ

Doutora em Direito pela Pontifícia Universidade Católica de São Paulo. Professora do Curso de Direito da Pontifícia Universidade Católica de São Paulo (PUC-SP) - São Paulo - SP- Brasil. E-mail:maitemoro@gmail.com. 
from each other. The difference in the Market guarantee the competition. The distinctive signs are identification and differentiation instruments for businessmen, their products ans services in the market. Also guaranteed in the Brazilian Constitution, the protection of distinctive signs secure ethical and equitable competition, also encouraging corporate sustainability and market competition. The trademark is the main element of diferentiation of the company nowadays. Although registration at the National Industrial Property Institute (Brazilian PTO) grants an exclusive use for a unique person/company, this right doesn't represent a distortion of freedom of competition, but a necessary element for mantaining and promoting competition.

Keywords: Constitution. Competition freedom. Free initiative. Industrial property. Distinctive signs. Trademarks.

\section{Introdução}

No âmbito empresarial, os empresários se valem de sinais distintivos para identificar e diferenciar a si mesmos, seus produtos e seus serviços dos inúmeros concorrentes existentes no mercado.

A Constituição Federal assegura proteção aos sinais distintivos por meio de seu art. $5^{\circ}$, inc. XXIX, como abaixo se observa:

Art. $5^{\circ}$ - Todos são iguais perante a lei, sem distinção de qualquer natureza, garantindo-se aos brasileiros e aos estrangeiros residentes no País a inviolabilidade do direito à vida, à liberdade, à igualdade, à segurança e à propriedade, nos termos seguintes: [...]

XXIX - a lei assegurará aos autores de inventos industriais privilégio temporário para sua utilização, bem como proteção às criações industriais, à propriedade das marcas, aos nomes de empresas e a outros signos distintivos, tendo em vista o interesse social e o desenvolvimento tecnológico do País (original não grifado).

Com fundamento nesse dispositivo constitucional, o legislador promulgou a Lei de Propriedade Industrial (Lei n. 9.279/96), que versa, 
dentre outros temas, sobre a proteção às marcas e outros sinais distintivos, bem como acerca da repressão à concorrência desleal.

À primeira vista, tem-se a ideia de que o ordenamento jurídico, ao garantir o uso exclusivo de um sinal distintivo a um determinado empresário, estaria lhe fazendo simplesmente um favor, concedendoIhe um privilégio. Um privilégio em detrimento dos demais concorrentes do mercado. Entretanto, uma análise mais apurada e aprofundada do tema mostra que essa premissa não necessariamente é verdadeira.

A relação entre sinais distintivos e direito da concorrência, especialmente repressão à concorrência desleal, é um assunto relacionado, mas não necessariamente destrinchado pela doutrina, sendo de extrema importância para compreender o papel e a exata função e limite da proteção desses sinais distintivos, considerados ativos imateriais dos concorrentes.

\section{0 princípio da livre concorrência}

Expressamente acolhida no art. 170, inc. IV, da CF, a livre concorrência é tida como um princípio da ordem econômica nacional.
Art. 170 - A ordem econômica, fundada na valorização do trabalho humano e na livre iniciativa, tem por fim assegurar a todos existência digna, conforme os ditames da justiça social, observados os seguintes princípios:
[...]
IV - livre concorrência.

Por este princípio constitucional, garante-se aos agentes econômicos a possibilidade de competir no segmento de mercado que escolherem. Do ponto de vista político, livre concorrência é garantia de oportunidades iguais a todos os competidores. Em um panorama mais amplo, pode ser entendida como uma decorrência lógica da opção pelo modelo econômico pautado na livre iniciativa. Entretanto, no texto constitucional, encontram-se ambas destacadas, outorgando-se à livre 
concorrência uma grande importância no sistema (TAVARES, 2003, p.254)

Assegurar a livre concorrência em um mercado tem por objetivo não só manter a livre iniciativa para que outros empresários tenham condições de adentrar o mesmo mercado, mas também manter a competição. Afinal, se não houvesse livre concorrência e livre iniciativa, estar-se-ia falando de mercado sem restrições ao monopólio e aos abusos.

Não basta, portanto, estabelecer uma regra de livre concorrência para manter a livre iniciativa e a competição mercadológica. Afinal, para competir e ganhar mercado os concorrentes não medem esforços, muitas vezes abusando e/ou praticando atos que visam justamente aniquilar a concorrência. Nesse sentido, Nuno P. de Carvalho (1995, p. 26-27) diz que "[...][h]á abuso quando o empresário elimina (ou tende a eliminar) a concorrência, isto é, elimina (ou tende a eliminar) o próprio exercício das forças competitivas [...]. Isto, quer ele empregue um meio fraudulento ou não".

A rigor, a própria Constituição Federal estabelece limites à livre concorrência, quando, em seu art. $173, \S 4^{\circ}$, estabelece que deverá ser reprimido por lei o abuso de poder econômico que tenha por objetivo a dominação de mercados, a eliminação da concorrência ou o aumento arbitrário de lucros. O Estado fez isso, tendo regulado essa situação primeiramente na Lei 8.884/94, conhecida como lei antitruste, a qual alçou o Conselho Administrativo de Defesa Econômica (CADE) à categoria de autarquia e dispõe sobre a prevenção e repressão contra a ordem econômica. Atualmente, essa lei, ainda que não expressamente revogada, foi quase inteiramente substituída pela Lei 12.529/11, que estruturou o Sistema Brasileiro do Direito da Concorrência.

Resta clara a necessidade que se tem de tutelar o mercado para garantir que os empresários possam efetivamente concorrer. A proteção do mercado, portanto, visa garantir os princípios da ordem econômica assegurados na Constituição Federal. As lições de Gama Cerqueira (1946, p. 81) também vão nessa linha: 
a livre concorrência econômica é conseqüência da liberdade de comércio e indústria e age como elemento do progresso econômico de cada país. Mas degenera, transformando-se em agente perturbador desse progresso, quando os comerciantes e industriais, no afã de vencerem seus competidores lançam mão de práticas e métodos ilícitos ou desleais. Daí a necessidade de regulamentar a concorrência, coibindo os abusos da liberdade individual e mantendo a livre concorrência dentro de seus limites naturais. Entretanto, é difícil, senão impossível, como bem se compreende, prever, na lei, todos os casos e formas de concorrência desleal.

A livre concorrência deve ser entendida como fundamento mais amplo para a proteção do livre mercado e da deslealdade concorrencial.

É relevante ressaltar ainda que a livre concorrência, além das garantias aos concorrentes, indiretamente também favorece aos consumidores e à melhora e evolução dos produtos e serviços que são oferecidos, pois os concorrentes têm interesse e buscam inovar e se diferenciar na ânsia de angariar maior clientela.

\section{Concorrência, ética e sustentabilidade}

No entanto, como visto acima, "há meios e meios de concorrer". Em outras palavras, para se ganhar clientela e fama no mercado, os competidores às vezes vão além da criatividade, atuando de forma moralmente questionável em relação a seus concorrentes. Nesse contexto, enquadra-se a questão da lealdade e da honestidade na concorrência.

Práticas consideradas desleais entre os próprios competidores, com vistas a angariar clientela alheia, também podem ser consideradas um atentado à livre concorrência. Nesse caso, não se vislumbra, a princípio, um risco ao mercado como um todo, mas um risco à saúde da concorrência em um determinado segmento do mercado. 
Vale lembrar que o legislador, ao se preocupar com a ética na concorrência, preocupa-se também com a sustentabilidade no mercado. Recordam-se aqui as palavras de José Roberto Nalini (2011, p.128), que ressalta como a sustentabilidade entrou na agenda empresarial, dizendo que:

Sustentabilidade entrou na agenda empresarial e dela não mais sairá. Seja por autoconvencimento, fruto de uma consciência reta, seja por exigência do consumidor [...] Sustentabilidade é uma concepção eminentemente ética. $O$ aspecto moral está em pensar no próximo. Não se imagina que a empresa só pense no próximo. Ela é uma organização que visa o lucro. Não é entidade filantrópica. Mas pode pensar também no próximo. Uma concepção adequada de sustentabilidade levam em conta os dois aspectos: obter lucro e disseminar boas práticas. (Grifo original).

Nesse ponto, pode-se acrescentar que a honestidade, a moralidade e o respeito ao próximo no âmbito empresarial também devem ser observados como uma forma de sustentabilidade empresarial.

Denominados atos de concorrência desleal, encontram-se regulados no ordenamento jurídico brasileiro na Lei da Propriedade Industrial (Lei 9.279/96). Esta, em seu artigo $2^{\circ}$, estabelece que "a proteção dos direitos relativos à propriedade industrial, considerado o seu interesse social e o desenvolvimento tecnológico e econômico do País, efetua-se mediante: [...] V - repressão à concorrência desleal".

O ato de concorrência desleal é rechaçado pelo artigo 195, inc. III, da Lei da Propriedade Industrial, que pode ser considerado uma regra geral para a disciplina, assim dispondo: "Art. 195 - Comete crime de concorrência desleal quem: [...]. III - emprega meio fraudulento, para desviar, em proveito próprio ou alheio, clientela de outrem; [...]".

Além da hipótese do art. 195, inc. III, que abarca uma série de situações, os demais incisos do art. 195 tratam de casos mais específicos, dentre os quais: a publicação de falsa afirmação que prejudique o concorrente; o uso ou divulgação de conhecimentos ou dados confidenciais de uma empresa; etc. Já o art. 209 da mesma lei, 
tendo-se consciência da impossibilidade de se prever todo e qualquer ato desleal nessa seara, possibilita reprimir civilmente atos de concorrência desleal.

Como prática desonrosa que é o emprego de meios desonestos de concorrência, o ordenamento coíbe frontalmente a concorrência desleal, não apenas por meio da Lei $n^{\circ}$ 9.279/96, como também de tratados internacionais. Esse o caso da Convenção da União de Paris (CUP), tratado acolhido pelo Direito pátrio, ex vi do Decreto $\mathrm{n}^{\circ} 1.263$, de 10 de outubro de 1994, que, em seu artigo 10 bis, preconiza o seguinte:

Artigo 10 bis. 1. Os países da União obrigam-se a assegurar aos nacionais dos países da União proteção efetiva contra a concorrência desleal.

2. Constitui ato de concorrência desleal qualquer ato de concorrência contrário aos usos honestos em matéria industrial ou comercial.

3. Deverão proibir-se particularmente:

$1^{\circ}$ Todos os atos suscetíveis de, por qualquer meio, estabelecer confusão com o estabelecimento, os produtos ou a atividade industrial ou comercial de um concorrente; [...]. (original não grifado).

Como se percebe, na hipótese de concorrência desleal, analisase o comportamento e intenção do concorrente frente aos elementos identificadores de seus concorrentes. Não se aceita a concorrência em que o um concorrente usa de qualquer meio para angariar a clientela alheia, importa também a forma como se concorre. Pode-se concorrer desde que observados princípios éticos e leais em relação aos demais concorrentes.

Em outras palavras, pode-se dizer que a liberdade concorrencial encontra barreiras na medida em que os operadores do mercado passam a exercê-la sem escrúpulos. Bittar (1981, p.31) explica que:

o princípio da livre concorrência, que governa a atividade empresarial, encontra balizas em preceitos de moral, exigidos, mesmo, em textos expressos, para a perfeita higidez de seu desenvolvimento, em que avultam a honestidade e a lealdade (original não grifado). 
A concorrência desleal desenvolveu-se inicialmente como um instituto focado nos interesses privados dos concorrentes. Com a evolução do direito, que cada vez mais inter-relaciona o direito privado com o direito público, não ficou de fora a avaliação das regras de repressão à concorrência desleal.

Compreender a concorrência desleal como um instituto que simplesmente se preocupa com interesses privados em jogo não é a tendência atual. A concorrência desleal tem sido vista sob um olhar muito mais amplo e integrado à ordem jurídica como um todo. Tratase da denominada concepção integrada da concorrência desleal, originada na doutrina alemã, sob a qual se visa a proteger pelas regras de concorrência desleal, de forma conjunta, interesses públicos, interesses dos concorrentes e o interesse dos consumidores. Conforme o ensinamento de José Oliveira Ascensão (2002, p.45):

Tradicionalmente, a concorrência desleal surge como um instituto que visa a defesa dos concorrentes. Seriam assim interesses privados que estariam prevalentemente em causa.

Mas a evolução, trazendo preocupação acrescida da defesa do consumidor, veio fazer avultar casos em que seria justamente essa defesa que justificaria a concorrência desleal.

E por outro lado, acentuou-se que o interesse público justificaria igualmente a intervenção a título de concorrência desleal: com a consideração de que não seria adequado obter vantagens na concorrência à custa da postergação de interesses gerais.

Ana Clara A. de Amorim (2009, p.39) também ensina nesse sentido:

Se a relevância econômico-social do instituto da concorrência desleal resulta de a mesma procurar garantir o equilíbrio nas relações de mercado, haverá que tutelar a expectativa de cada empresário vir a conseguir, no exercício da actividade económica, todos os resultados decorrentes do seu esforço. Ora, hoje e cada vez mais, percebem-se 
novas fórmulas de comportamentos desleais, destinadas a cativar os consumidores, mediante a usurpação da imagem de determinados sinais distintivos notórios e do resultado do trabalho alheio, e têm lugar sobretudo contornando os espaços de proibição previstos na lei de forma expressa, em particular, os direitos privativos e a susceptibilidade de confusão.

Ademais, reforçam essa linha de pensamento as diretrizes do Código de Proteção e Defesa do Consumidor (Lei 8.078/90) que, preocupado com os prejuízos que possam vir a sofrer os consumidores em vista de falsas associações, determina no inciso $\mathrm{VI}$, do artigo $4^{\circ}$, o seguinte:

Art. $4^{\circ}$-APolítica Nacional das Relações de Consumo tem por objetivo o atendimento das necessidades dos consumidores, o respeito à sua dignidade, saúde e segurança, a proteção de seus interesses econômicos, a melhoria da sua qualidade de vida, bem como a transparência e harmonia das relações de consumo, atendidos os seguintes princípio: [...]

VI - coibição e repressão eficientes de todos os abusos praticados no mercado de consumo, inclusive a concorrência desleal e utilização indevida de inventos e criações industriais das marcas e nomes comerciais e signos distintivos, que possam causar prejuízos aos consumidores. (Original não grifado)

Tem-se, portanto, que os casos de concorrência desleal, apesar de gerados em um âmbito particular, também têm reflexos no interesse público, que ultrapassam a relação particular. Logo, o prejuízo vai além da relação entre os concorrentes, podendo gerar também prejuízos aos consumidores e ao mercado como um todo.

Assim, todos aqueles meios utilizados na concorrência e considerados desleais, diferentemente do enunciado da norma, não estimulam a concorrência, e sim a degeneram, a maculam, por isso devem ser reprimidos. Ressalta-se então o um sub-princípio decorrente da liberdade concorrencial, para resguardar a concorrência saudável, que é o princípio da repressão à concorrência desleal. 


\section{A importância dos sinais distintivos}

Dentro desse cenário concorrencial até agora exposto, os empresários se utilizam de sinais distintivos para identificar e diferenciar a si mesmos, seus produtos e seus serviços dos inúmeros concorrentes existentes no mercado.

Os doutrinadores franceses Albert Chavanne e Jean-Jacques Burst (1998, p.471) ensinam que os sinais distintivos "são os meios fonéticos ou visuais que permitem à clientela reconhecer os produtos, serviços ou estabelecimentos que ela procura e de os distinguir dos produtos, serviços ou estabelecimentos similares".

Compõem os sinais distintivos um dos segmentos protegidos pela propriedade intelectual e englobam as marcas, os nomes empresariais, os títulos de estabelecimentos, as insígnias, as indicações geográficas e, mais recentemente, os nomes de domínio.

Como já mencionado o artigo $5^{\circ}$, inciso XXIX, da Constituição Federal, assegura a proteção aos sinais distintivos no ordenamento pátrio, cabendo observar que, em tal dispositivo, há a preocupação em assegurar igualmente a proteção a outros sinais distintivos, que não sejam necessariamente as marcas e nomes empresariais. "Outros sinais distintivos" podem englobar diferentes formas de expressão e identificação de uma empresa, seus produtos, serviços ou estabelecimentos, incluindo, dentre outros, a indicação geográfica ou o trade dress adotado.

\subsection{Marca - o sinal distintivo mais valorizado na atualidade}

Como sinal distintivo, a marca facilita a identificação de produtos e/ou serviços dentro do mercado, possibilitando, ao mesmo tempo, o seu reconhecimento pelo público consumidor e a diferenciação de seus concorrentes. Identificar e diferenciar são, portanto, características intrínsecas das marcas, as quais constituem, atualmente, o principal e mais valorizado elemento distintivo imaterial de uma empresa. 
Ao definir marcas, o tratadista João da Gama Cerqueira (1946, p.365-366; 345) entende que se trata de "todo sinal distintivo apôsto facultativamente aos produtos e artigos das indústrias em geral para identificá-los e diferençá-los de outros idênticos ou semelhantes de origem diversa". As marcas identificam e diferenciam os produtos e serviços.

A marca como sinal utilizado pelos empresários, na seara negocial e também concorrencial, exerce inúmeras funções econômicas no mercado. No entanto, nem todas as funções que se observam no campo econômico são juridicamente relevantes.

Carvalho de Mendonça e Gama Cerqueira (1946, p. 348) já reconheciam a função econômica que exerce uma marca, ressaltando que a marca não tem a mera função de distinguir produtos ou serviços.

Para Carvalho de Mendonça (1955, p. 217): "Ellas assumem valiosa função economica, garantindo o trabalho e o esforço humano, representando factor do trafego e tornando-se elemento de êxito e de segurança às transações". Entretanto, Gama Cerqueira afirmou que a marca foi criada "para segurança dos direitos dos comerciantes e industriais sobre o resultado de seu trabalho".

Constata-se que a marca, como o bem intelectual, que sem dúvida é, tem uma finalidade econômica, como afirma o francês Paul Mathély (1994, p. 12): "La marque est, pour l'entreprise, d'une utilité économique décisive". Tal constatação pode ser confirmada pelo estudo publicado na Revista da OMPI (2002, p. 5) que diz: "La propiedad intelectual (las patentes, las marcas, los secretos comerciales, los diseños industriales, las indicaciones geográficas y el derecho de autor) es un activo, $y$ como otros tipos de propiedad, puede crearse y gestionarse con fines económicos"1.

Revista de la OMPI - Organización Mundial de la Propiedad Intelectual. Políticas de Propiedad Intelectual. Genebra, out. 2002, p. 5. Tradução livre do original: "A propriedade intelectual (as patentes, as marcas, os segredos comerciais, os desenhos industriais, as indicações geográficas e o direito de autor) é um ativo, e como outros tipos de propriedade, pode criar-se e gerenciar-se com fins econômicos". 
Para poder exercer a função econômica, a rigor, o sinal precisa exercer uma outra função, esta sim juridicamente protegida, que é a função distintiva.

\subsubsection{A proteção da marca e de sua função distintiva}

O artigo 122 da Lei $n^{\circ}$ 9.279/96, que estabelece o que se pode registrar como marca, aponta a necessidade de se tratar de um sinal distintivo: "Art. 122 - São suscetíveis de registro como marca os sinais distintivos visualmente perceptíveis, não compreendidos nas proibições legais".

Para se obter o registro de marca no Brasil, os sinais devem cumprir os requisitos de validade. Os requisitos de validade de marca depreendem-se da legislação pertinente. A lei brasileira somente aceita como marcas "sinais visualmente perceptíveis", o que já constitui uma restrição ao registro, mas, além disso, os sinais devem ser distintivos, disponíveis ${ }^{2}$ e lícitos ${ }^{3}$, além de respeitar os princípios da territorialidade, da especialidade, e de seus titulares deverem exercer, efetiva e licitamente, a atividade para a qual a marca é requerida (art. 128, LPI).

A distintividade é requisito essencial para o registro de uma marca. Um sinal para ser passível de registro como marca deve possibilitar a identificação dos produtos ou serviços que assinala dentre os produtos e serviços ofertados no mercado. Em outras palavras, o sinal deve ser capaz de distinguir os produtos e serviços de seu titular no mercado. Para tanto, o sinal eleito deve ter capacidade distintiva. Isso significa que o sinal não pode se confundir ou descrever o produto ou serviço assinalado, ou mesmo guardar relação com características desses produtos ou serviços.

2 Disponível é o sinal que ainda não foi apropriado por terceiro para identificar produto ou serviço idêntico, semelhante ou afim ao pretendido. Mas, não é somente a anterioridade de marcas que é afetada pela disponibilidade, a anterioridade de outros sinais distintivos e de direitos de terceiros que possam impedir a apropriação com exclusividade do sinal marcário por quem o deseje, também configura obstáculo.

3 Lícito, por fim, é o sinal que não contraria a ordem pública, moral e bons costumes, bem comonão possui caráter enganoso. 
Para ser considerada distintiva como marca, uma expressão deve ter capacidade de distintiguir o produto e/ou serviço que irá assinalar. A falta de distintividade da expressão desautoriza a sua apropriação com exclusividade por qualquer pessoa, tanto que a Lei 9.279/96 (LPI), em seu art. 124, inc. VI, estabelece que:

Art. 124 - Não são registráveis como marca:

$[\ldots]$

$\mathrm{VI}$ - sinal de caráter genérico, necessário, comum, vulgar ou simplesmente descritivo, quando tiver relação com o produto ou serviço a distinguir, ou aquele empregado comumente para designar uma característica do produto ou serviço, quanto à natureza, nacionalidade, peso, valor, qualidade e época de produção ou de prestação de serviço, salvo quando revestidos de suficiente forma distintiva.

Em outras palavras, não é registrável o sinal que, de alguma forma, descreva o produto ou serviço que visa distinguir, ou ainda que tenha alguma relação com características de tais produtos ou serviços. Essa proibição se justifica pela necessidade que os concorrentes têm de utilizar esses termos para designar e/ou qualificar seus produtos.

O registro validamente outorgado pelo INPI, garantido por meio da acima mencionada, garante ao titular a propriedade da marca, que corresponde ao direito de utilizá-la exclusivamente no território brasileiro, para assinalar os produtos ou serviços identificados. É o que preceitua o artigo 129, caput, da Lei da Propriedade Industrial. "Art. 129. A propriedade da marca adquire-se pelo registro validamente expedido, conforme as disposições desta lei,sendo assegurado ao titular seu uso exclusivo em todo o território nacional, [...]" (original não grifado).

Como consequência do direito de uso exclusivo de uma marca está o direito de impedir que terceiros façam o uso da marca sem o prévio consentimento de seu titular. Lembram Bertone e Cabanellas (2003, p.33) que "el eje del derecho concedido al titular de una marca es el jus prohibendi respecto del uso de ese signo por terceros". A exclusividade dada pelo registro é importante para que a marca possa 
exercer sua função distintiva. Segundo Franceschelli (1988, p.231) “[...] todos parecem estar de acordo que a primeira e mais importante função da marca é a distintiva [...]"4.

Diretamente ligado ao exercício da função principal da marca, qual seja a distintiva, está a capacidade distintiva do sinal. A proteção de uma marca pelo registro garante ao titular a exclusividade de sua utilização, justamente visando preservar sua função distintiva no mercado e assim possibilitar que os consumidores consigam reconhecer os produtos e serviços identificados por elas.

$\mathrm{O}$ art. 123, inc. I, da LPI confirma o exercício da função distintiva em nosso ordenamento quando traça como objetivo de uma marca de produto ou serviço como "distinguir produto ou serviço, de outro idêntico, semelhante ou afim de origem diversa". Depreende-se do texto legal que a função distintiva da marca, como instituto jurídico, é a realização do ato de distinguir, com vistas a diferenciar produtos e serviços de outros idênticos, semelhantes ou afins, de origem diversa.

Consiste a função distintiva da marca na atividade de diferenciar um produto ou serviço no mercado. Se não existissem as marcas, os consumidores que tivessem uma experiência anterior com um determinado produto não o conseguiriam em uma nova oportunidade identificá-lo dentre os concorrentes. Logo, a possibilidade de exercer a função distintiva é necessária para que um sinal seja juridicamente considerado como marca.

Em última análise, a lei busca afastar o risco de confusão ou associação de marcas de diferentes titulares e manter uma concorrência leal e digna entre os concorrentes no mercado. Protegendo as marcas, o legislador reprime também a concorrência desleal.

Não por acaso vedou o legislador expressamente no artigo 124, inciso XIX, da Lei n 9.279/96, a imitação e a reprodução da marca.

Tradução livre do original: "[...]tutti sembrano essere d'accordo che la prima e più importante funzione del marchio è quella distintiva[...]" 
Art. 124 - Não são registráveis como marca:

$[\ldots]$

XIX - reprodução ou imitação, no todo ou em parte, ainda que com acréscimo, de marca alheia registrada, para distinguir ou certificar produto ou serviço idêntico, semelhante ou afim, suscetível de causar confusão ou associacão com marca alheia. (original não grifado)

Com esse dispositivo, busca a referida lei evitar que a clientela de um determinado comerciante ou industrial seja desviada para outro, em razão de fraude, engodo, erro ou confusão, oriundo da reprodução ou imitação de marca registrada.

Do exposto, depreende-se que a proteção dada aos sinais distintivos nada mais objetiva do que garantir a possibilidade a cada concorrente de se identificar e diferenciar no mercado, assegurando ao consumidor a possibilidade de escolha e, por consequência, a manutenção da concorrência no mercado.

\section{Exclusividade x livre concorrência - Um aparente paradoxo}

Ainda que se outorgue um uso exclusivo sobre os sinais distintivos, como no caso das marcas, para um único concorrente no mercado, diferentemente do que primeiramente possa parecer essa exclusividade, quando bem avaliada e outorgada, não impede a concorrência; pelo contrário, promove-a. Promove-a, pois, protegendo-se os sinais distintivos criados pelas empresas, preserva-se e tutela-se a possibilidade de competir no mercado. Afinal, se não se permite a diferença, não se permite a identificação dos produtos pelos consumidores. A rigor, o que se visa proteger e garantir é a possibilidade de se identificar e diferenciar , desde que de forma honesta, leal. São claros os ensinamentos de Nuno P. de Carvalho (2009, p. 4) nesse sentido:

[T]odo comerciante, todo o artesão necessita de proteger e de afirmar a sua individualidade para poder exercer seu ofício. É afirmando e usando essa individualidade que as empresas atraem e mantêm suas clientelas. Na ausência dos elementos intangíveis que distinguem uma empresa de 
outra, os clientes não podem tomar uma decisão informada sobre onde comprar produtos e serviços. Esses elementos são de muitos tipos: desde os nomes que identificam e distinguem as empresas e os seus produtos ou serviços até os próprios produtos e serviços e os conhecimentos que eles incorporam ou pressupõem.

Para que essa premissa seja verdadeira é fundamental ter como contexto uma economia de livre mercado, baseada na livre concorrência e na livre iniciativa, que constituem os princípios da ordem econômica brasileira (art. 170 da CF).

A proteção aos sinais distintivos colabora, portanto, para garantir a livre concorrência. Isso porque garantir ao empresário a possibilidade de se identificar e diferenciar no mercado Ihe dá segurança para empreender, para inovar. Em paralelo, a tutela dos sinais distintivos auxilia na repressão aos atos de concorrência praticados em desacordo com os princípios éticos, garantindo assim uma competição honesta. A lealdade na competição é fundamental para se assegurar a liberdade de iniciativa.

Logo, a aproximação indevida dos sinais distintivos que identificam um determinado concorrente em relação aos demais no mercado, dependendo do contexto e do caso, devem ser objeto de repressão legal.

\section{Conclusão}

Combinando os princípios norteadores da ordem econômica nacional e o inciso XXIX do art. $5^{\circ}$ da Constituição, que assegura a proteção da propriedade industrial no Brasil, conclui-se que o ordenamento jurídico nacional se preocupa tanto com a tutela do livre mercado, reprimindo o abuso do poder econômico, quanto em assegurar a lealdade dos concorrentes, garantindo a exclusividade de uso de bens imateriais, como ativos intangíveis diferenciadores ${ }^{6}$.

6 Termo cunhado por Nuno Pires de Carvalho (2009, p. 3 e seguintes). 
Quando se fala em liberdade de concorrência, fala-se de estímulo à concorrência entre os agentes do mercado. $O$ fato de garantir a proteção aos sinais distintivos colabora para garantir também a livre concorrência, princípio da ordem econômica igualmente tutelado na Constituição Federal (art. 170, inc. IV), pois garantir ao empresário a possibilidade de se identificar e diferenciar no mercado lhe dá segurança para empreender, para inovar. A proteção aos sinais distintivos repreende atos de concorrência que sejam praticados deslealmente ou desonestamente.

Sob outra ótica, a proteção aos sinais distintivos garante a liberdade de escolha do consumidor. Afinal, a diferença dos produtos, garantida pela proteção aos sinais distintivos, permite também que os consumidores possam identificá-los.

Ao manter regras de proteção aos sinais distintivos no ordenamento, o legislador preserva um andar correto, a honestidade no mercado, garantindo, portanto, a ética e a sustentabilidade da atividade empresarial em seu território.

\section{Referências}

AMORIM, Ana Clara A. de. Parasitismo Económico e Direito. Coimbra: Almedina, 2009.

ASCENSÃO, José de Oliveira. Concorrência desleal. Coimbra: Almedina, 2002.

BARCELLOS, Milton Lucídio Leão. Propriedade industrial \& Constituição: As teorias preponderantes e sua interpretação na realidade brasileira. Porto Alegre: Livraria do Advogado, 2007.

BERTONE, Luis Eduardo; CABANELLAS DE LAS CUEVAS, Guillermo. Derecho de marcas. 2. ed. atual., rev. e ampl. Buenos Aires: Heliasta, 2003. v. I.

BITTAR, Carlos Alberto. A concorrência desleal e a confusão entre produtos. Revista dos Tribunais, vol. 550, 1981. 
CARVALHO, Nuno T. P. As concentrações de empresas no direito antitruste. São Paulo: Resenha Tributária, 1995.

CARVALHO, Nuno T. P. A estrutura dos sistemas de patentes e de marcas - passado, presente e futuro. Rio de Janeiro: Lumen Juris, 2009.

CARVALHO DE MENDONÇA, J.X. Tratado de direito comercial brasileiro. 5. ed. Rio de Janeiro: Freitas Bastos, v. 5, 1955.

CERQUEIRA, João da Gama. Tratado da propriedade industrial. Rio de Janeiro: Forense, 1946. t.I.

CHAVANNE, Albert; BURST, Jean-Jacques. Droit de la propriété industrielle. 5. ed. Paris: Dalloz, 1998.

FRANCESCHELLI, Remo. Sui marchi di impresa. 4. ed. Milano: Giuffrè, 1988.

REVISTA DE LA OMPI - Organización Mundial de la Propiedad Intelectual. Políticas de propiedad intelectual. Genebra, n. 10, out./ 2002, p. 5-9. Disponível em: <http://www.wipo.int/export/sites/www/ wipo_magazine/es/pdf/2002/wipo_pub_121_2002_10.pdf>.

MATHÉLY, Paul Mathély. Le nouveau droit français des marques. Paris: J.N.A., 1994.

MORO, Maitê Cecilia Fabbri. Direito de marcas - Abordagem das marcas notórias na Lei 9.279/96 e nos acordos internacionais. São Paulo: RT, 2003.

MORO, Maitê Cecilia Fabbri. Marcas tridimensionais: sua proteção e os aparentes conflitos com a proteção outorgada por outros institutos da propriedade intelectual. São Paulo: Saraiva, 2009.

NALINI, José Roberto. Sustentabilidade e ética empresarial. In:

SILVEIRA, Vladmir Oliveira da (Coord.) Empresa, sustentabilidade e funcionalização do Direito. São Paulo: Revista dos Tribunais, 2011. v.2. p. 119-143. (Col. Justiça, Empresa e Sustentabilidade).

TAVARES, André Ramos. Direito constitucional econômico. São Paulo: Método, 2003.

Recebido em: 01/06/2015

Aprovado em: 25/05/2016 